\title{
RESÍDUOS GERADOS EM ANÁLISES CLÍNICAS MICROBIOLÓGICAS E SAÚDE SOCIOAMBIENTAL
}

Mônica Naves BARCELOS ${ }^{1}$

João Paulo Pereira ROSA²

\author{
${ }^{1}$ Mestre em Educação, Especialista em Análises Clínicas. \\ ${ }^{2}$ Mestre, Coordenador e Docente do Curso de Farmácia da UninCor.
}

\author{
Autor correspondente \\ Prof. Ms. Mônica Naves Barcelos \\ monicanavesbarcelos@yahoo.com.br
}

Recebido em: 08/10/2015 - Aprovado em: 17/04/2016 - Disponibilizado em: 30/07/2016

\begin{abstract}
RESUMO
A produção de resíduos de serviços de saúde (RSS), como os provenientes de Laboratórios de Análises Clínicas, é uma problemática social que deve ser considerada frente à crise ambiental que vivenciamos atualmente. Neste contexto, esta pesquisa objetivou despertar sobre a importância da interface entre as Análises Clínicas e a Saúde socioambiental no descarte de resíduos microbiológicos. A justificativa se dá devido à carência de produções científicas que abordem a temática dos RSS e suas interfaces com a saúde socioambiental. A metodologia do presente trabalho consistiu na realização de uma Revisão da Literatura, a partir de um levantamento do que há disponível sobre o assunto. A pesquisa realizada mostrou que há necessidade de aprofundamento de discussões sobre o tema quanto à interface entre as Análises Clínicas Microbiológicas, RSS e Saúde socioambiental, num estudo categórico e integrador entre: os tipos de resíduos provenientes de cada tipo de Análise Clínica Microbiológica (bacteriológica, virológica, parasitológica, fúngicas); os microrganismos veiculados nos resíduos produzidos por Análises Clínicas Microbiológicas; e as consequências socioambientais como resultado da veiculação de microrganismos provenientes de resíduos advindos de Análises Clínicas Laboratoriais.
\end{abstract}

Palavras-chave: Contaminação, Descarte, Laboratório, Microbiologia. Ambiental.

\section{Waste generated in microbiological clinical analyses and environmental health}

\begin{abstract}
The production of medical waste (MW), such as that from Clinical Analysis Laboratories, is a social issue that should be considered when faced with crisis. In this context, this study aimed to awaken the importance of an interface between Clinical Analysis and environmental health in the disposal of microbiological waste. This study is justified by the lack of scientific publications that address the issue of MW and its interfaces with environmental health. The methodology of this work consisted of a Literature Review based on a survey of papers available on the subject. The survey showed the need to deepen discussions on the subject regarding the interface between Clinical Microbiological Analysis, MW and environmental health. It also presented a categorical and integrative study between the types of waste from each type of Clinical Microbiological Analysis (bacteriological, virological, parasitological and fungal), the microorganisms conveyed in the waste produced by Clinical Microbiological analyzes, and the social and environmental consequences, because of the transmission of microorganisms arising from Clinical Laboratory Analysis waste.
\end{abstract}

Keywords: Contamination, Waste, Laboratory, Microbiology. Environmental. 


\section{INTRODUÇÃO}

A produção de resíduos de serviços de saúde (RSS), como os provenientes de Laboratórios de Análises Clínicas, é uma problemática social que deve ser considerada perante a crise ambiental que vivenciamos atualmente. Isso, porque a presença de agentes biológicos em resíduos descartados pode resultar na transmissão direta e indireta de doenças, devido à contaminação do meio ambiente.

Com formação em Farmácia Bioquímica, o presente estudo foi desenvolvido com base em interesse pessoal pela questão socioambiental, interrelacionando-a com as Análises Clínicas Microbiológicas, uma vez que estas geram resíduos que se não tratados de forma adequada, contaminam o meio ambiente, refletindo na saúde pública. Deste contexto, advém a expressão saúde socioambiental.

Assim, a importância de se desenvolver este trabalho se justifica pela carência de produções científicas que abordem a temática dos RSS e suas interfaces com a saúde socioambiental. Os estudos destacam a necessidade de capacitar os profissionais de saúde para o correto gerenciamento dos resíduos, visto que parte dos profissionais não sabem o que são resíduos, tampouco referem importância ao correto manuseio destes nas práticas de saúde (MORESCHI et al, 2014).
Segundo Moreschi et al (2014), profissionais de saúde reconhecem que existe negligência nos procedimentos realizados que geram impacto ambiental e suas repercussões para a sociedade. Essa negligência acontece por tratar-se de mudança de paradigma, o que resulta em resistências e desafios. Nesta circunstância, tomando por base as concepções de Spironello et al (2012), os desafios envolvem o processo de sensibilização para que a conscientização ocorra, focando não apenas em mudanças de comportamentos, mas sim, na tomada de atitudes advindas de transformações de valores. Esse processo envolve reflexão crítica sobre o manejo inadequado dos resíduos de Análises Clínicas Microbiológicas, bem como suas consequências à saúde socioambiental.

Diante disso, este trabalho tem como objetivo despertar sobre a importância da interface entre as Análises Clínicas e a Saúde socioambiental no descarte de resíduos microbiológicos.

\section{METODOLOGIA}

A metodologia do presente trabalho consistiu na realização de uma Revisão da Literatura (BENTO, 2012), a partir de um levantamento sobre o que há disponível sobre o assunto, de modo a atingir o objetivo geral.

Bento (2012) aponta que a realização de uma Revisão de Literatura é capaz de despertar no pesquisador, apreensões, ou, nas 
palavras do autor, inquietações que atormentam. Dentre elas, quando se deve concluir, ou seja, quando se sabe que já se tem o suficiente.

Sendo assim, o caminho metodológico seguido valeu-se de um levantamento de discursos de outros pesquisadores e estudiosos, não apenas para reconhecê-los, mas também para interagir com eles por meio de análise e categorização, a fim de evidenciar a relevância da pesquisa a ser realizada (SANTOS, 2012).

Neste âmbito, Lima complementa Santos (2012) expondo que categorizar é agrupar entidades (objetos, ideias, ações etc.) por semelhança, resultando na criação de um conhecimento novo. Segundo a autora, a análise envolve uma organização conceitual. Para ela, a organização conceitual, que está diretamente relacionada à capacidade de aprender, supõe a assimilação de novas informações.

\section{REVISÃO DE LITERATURA}

Como exposto por Moreschi et al (2014), há poucos trabalhos na literatura sobre a produção de RSS e seu reflexo na saúde socioambiental. Tal fato, segundo Peres et al (2014), tem motivado a formulação de políticas públicas específicas sobre o assunto, em cenários específicos da atuação profissional.

Segundo Cavalcanti et al (2009), o crescimento populacional tem levado a uma demanda crescente de pacientes em busca de serviços de saúde e, consequentemente, a um aumento na produção de resíduos desse setor. Dentre as unidades que mais sofrem esta pressão, encontram-se os Laboratórios de Análises Clínicas, que se enquadram como fonte geradora de resíduos, constituídos por uma variedade muito grande de tipos, tais como agulhas, seringas, gaze, lâminas, dentre outros, que geridos de forma inadequada podem oferecer riscos tanto àqueles indivíduos onde são gerados, quanto ao meio ambiente (SILVA, 2004).

Deste modo, o assunto RSS resulta em não apenas efeito ao ambiente no sentido natureza, daí a grande importância do assunto. Muller et al (2014) citando Lippel (2003) e Baierle (2012) apontam que os RSS, dentro desta dimensão maior, constituem um desafio com interfaces, uma vez que além das questões ambientais inerentes a qualquer tipo de resíduo, os RSS incorporam uma preocupação maior no que tange ao controle de infecções nos ambientes prestadores de serviços, nos aspectos da saúde individual/ocupacional e à saúde pública.

O Analista Clínico, portanto, deve ser provido de uma visão holística e não reducionista do assunto RSS.

Os Laboratórios de Análises Clínicas, de acordo com Cavalcanti et al (2009), são instituições da área de saúde de apoio ao diagnóstico, mas também são voltados a fornecer conselhos adicionais. Isto envolve aconselhamentos sobre a gestão e 
disposição racional dos mesmos para o seu próprio bem, para o bem da sociedade e do meio ambiente. Em outras palavras, em prol do não impacto ao ambiente e à saúde, dado que, segundo um artigo publicado no site da Organização Nacional de Acreditação, a gestão e a disposição inadequada dos resíduos sólidos causam impactos socioambientais, tais como degradação do solo, comprometimento dos corpos d'água e mananciais, intensificação de enchentes, contribuição para a poluição do ar e proliferação de vetores de doenças.

Aliás, durante a fase pré-analítica e analítica, gera-se não somente resíduos sólidos, mas também efluentes líquidos, que podem ocasionar riscos aos analistas clínicos (2008).

Costa e Araújo (2008) expõem em artigo, as principais normas legais pertinentes ao gerenciamento dos RSS. Enquanto a Resolução da ANVISA focaliza a saúde pública e prevenção de acidentes, a Resolução do CONAMA preocupa-se com o meio ambiente:

- RDC n ${ }^{\circ}$ 306/2004 da ANVISA: esta norma atualiza e complementa os procedimentos contidos na Resolução RDC $\mathrm{n}^{\circ}$ 33/2003 da ANVISA, trazendo aspectos básicos relacionados à elaboração de um plano de gerenciamento de resíduos, destacando as orientações para o manejo, desde a segregação, acondicionamento, identificação, transporte interno, armazenamento temporário, armazenamento externo, coleta, até a disposição final.

- Resolução CONAMA nº 358/2005: esta norma atualiza e complementa os procedimentos contidos na Resolução CONAMA $n^{\circ}$ 283/2001, relativos ao tratamento e disposição final dos RSS, enfatizando a necessidade da minimização da geração de resíduos e redução dos riscos ao meio ambiente.

Entretanto, como expõe Silva (2004) no Brasil, pouco se discute sobre o assunto. Não existem dados oficiais sobre a quantidade de RSS gerados no Brasil e sua destinação final. A coleta executada por grande parte dos municípios é parcial, o que contribui significativamente para esse desconhecimento (2011). Por isso, o Brasil, segundo Cavalcanti et al (2009), apresenta um quadro preocupante, onde as ações preventivas demonstram-se insuficientes, pois alguns resíduos ainda são gerenciados de forma inadequada, em muitos casos, coletados e dispostos conjuntamente com o lixo doméstico normal, oferecendo riscos à saúde pública e ao meio ambiente.

RSS de um Laboratório Clínico Microbiológico podem conter uma variedade de microrganismos que são patogênicos, como bactérias, vírus, fungos ou parasitos, como por exemplo, os agentes responsáveis por doenças do trato intestinal (Ascaris lumbricoides; Entamoeba coli; Schistosoma mansoni); o vírus causador da hepatite (principalmente do tipo B), pela sua 
capacidade de resistir em meio adverso; e o vírus causador da AIDS, mais pela comoção social que desperta, do que pelo risco associado aos resíduos, já que apresenta baixíssima resistência em condições adversas. Além desses, devem também ser referidos os microrganismos responsáveis por dermatites (SILVA, 2004).

Estes patógenos podem estar presentes em diversos materiais utilizados na coleta, transporte e análise de amostras, como resíduos infectantes (algodão, luvas etc.) e perfurocortantes (agulhas, ampolas etc.), que se descartados de forma inadequada, são capazes de provocar impacto no ambiente e à saúde (MORESCHI et al, 2014).

Costa e Araújo (2008) demonstram a classificação dos RSS segundo a RDC $\mathrm{n}^{\circ}$ 306/2004 da ANVISA e Resolução CONAMA n ${ }^{\circ}$ 358/2005 (Tabela 1).

Tabela 1 - Classificação dos RSS segundo a RDC no 306/2004 da ANVISA e Resolução CONAMA n ${ }^{\circ} 358 / 2005$.

\begin{tabular}{ll}
\hline \multirow{2}{*}{ Classe A } & Resíduos com a possível presença de agentes biológicos que por suas \\
& características de maior virulência ou concentração, podem apresentar risco de \\
& infecção. \\
& Resíduos contendo substâncias químicas que podem apresentar risco à saúde ou \\
& ao meio ambiente, dependendo de suas características de inflamabilidade, \\
Classe B & corrosividade, reatividade e toxicidade, incluindo os produtos conforme \\
& classificação da NBR n ${ }^{\circ} 10004$ da ABNT. \\
Classe C & Rejeitos radioativos. \\
Classe D & Resíduos que não apresentam risco biológico, químico ou radiológico à saúde \\
Classe E & ou ao meio ambiente.
\end{tabular}

*Fonte - Costa e Araújo (2008).

Costa e Araújo (2008) ainda apontam para o fato de que a identificação dos resíduos do grupo $\mathrm{D}$, destinados à reciclagem ou reutilização, deve ser adotada nos coletores e transportadores, usando código de cores e suas correspondentes nomeações, baseadas na Resolução CONAMA nº 275/2001: azul papéis; amarelo - metais; verde - vidros; vermelho - plásticos; marrom - resíduos orgânicos; e cinza - resíduo geral não reciclável ou contaminado não passível de separação.

Análises Clínicas Microbiológicas realizadas em pequenos laboratórios envolvem procedimentos bacteriológicos capazes de produzirem resíduos A, B, D, E. Isto pode ser constatado mediante artigo de 
Costa e Araújo (2008), cujos dizeres encontram-se inseridos na Tabela 2.

Tabela 2 - Grupos de resíduos laboratoriais e materiais utilizados nas análises clínicas.

\begin{tabular}{ll}
\hline & É representado por placas de petri contendo meio de \\
Grupo A & altura, coletores contendo restos de urina e fezes, luvas, \\
& algodão, gaze, swabs, espátulas, contaminados com \\
& sangue ou secreções. \\
& É representado pelos reagentes usados nas análises e os \\
& recipientes contaminados por estes, além dos efluentes \\
Grupo B & dos equipamentos automatizados. \\
& É representado por papéis, papelão, copos plásticos, \\
Grupo D recicláveis & garrafas plásticas, embalagens plásticas e caixas dos kits \\
& de reagentes não contaminados. \\
& É representado por papel toalha, papéis sanitários, restos \\
Grupo D não recicláveis & alimentares, papel laminado de embalagens dos kits de \\
& É reagentes e outros similares. \\
Grupo E (perfurocortantes) & vidros controle, calibradores, agulhas, escalpes, ampolas de \\
vidros quebrados no laboratório (pipetas, tubos de ensaio, \\
tubos de coleta de sangue) e outros similares.
\end{tabular}

*Fonte - Costa e Araújo (2008).

$\mathrm{Na}$ bacteriologia, por exemplo, Ainda segundo os autores, amostras segundo Walters et al (1998), há a ocorrência comumente enviadas ao laboratório de de técnicas laboratoriais que incluem culturas referência, incluem culturas de lesões, de de secreção de orofaringe e/ou testes rápidos para Streptococcus, culturas de urina e, sangue e amostras de escarro.

Análises Clínicas Microbiológicas ocasionalmente, testes para Neisseria também identificam parasitas através de gonorrhoeae. A amostra coletada do paciente, diversas amostras biológicas, conforme ou é semeada, isolada e identificada no local, demonstra a Tabela 3 .

ou é enviada a um laboratório de referência. 
Tabela 3 - Tipos de amostras necessárias para a detecção de parasitos.

\begin{tabular}{ll}
\hline Microrganismo & Amostra Biológica \\
\hline Trichomonas vaginalis & Urina, secreção vaginal, secreção uretral, \\
& secreção prostática \\
Entamoeba histolytica & Fezes \\
Giardia lamblia & Fezes \\
Cryptosporidium parvum (especialmente & Fezes e/ou escarro \\
importante em paciente imunodeprimidos) & \\
Enterobius vermiculares (oxiúro) & Fita adesiva anal \\
Necator americanos (ancilóstomo) & Fezes \\
Plasmodium (malária) & Sangue \\
Ascaris lumbricoides & Fezes \\
Entamoeba coli & Fezes \\
Schistosoma mansoni & Fezes
\end{tabular}

*Fonte - Tabela elaborada a partir de Walters et al (1998) e Silva (2004).

Vírus também são detectados em Análises Clínicas Microbiológicas, como influenza (gripe ou resfriado), rubéola, caxumba, sarampo, vírus Epstein-Barr (mononucleose infecciosa) e herpes (WALTERS et al, 1998). Conforme os autores houve um aumento do interesse laboratorial em Análises Clínicas quanto à resposta virológica, a partir da descoberta do vírus da imunodeficiência humana (HIV) e do vírus do papiloma humano (HPV), por causa da demanda de diagnóstico mais rápido. Além disso, pelo aumento dos casos de hepatite B, que pode vir a ser uma doença fatal ou crônica.

Embora pequenos laboratórios não disponham de meios para realizar a maioria das Análises Microbiológicas de resposta virológica, são capazes de realizar coletas de amostras e transporte devidamente padronizados pelo laboratório de referência (WALTERS et al, 1998).

Outros microrganismos que podem ser identificados por Análises Clínicas Microbiológicas correspondem aos fungos. Infecções fúngicas, que segundo Walters et al (1998) são denominadas micoses. De acordo com a informação presente no site do Centro de Análises Clínicas (CEACLIN), as amostras biológicas necessárias para Análises Clínicas Microbiológicas Fúngicas incluem escamas de pele, unhas e pelos (micoses superficiais e cutâneas); o aspirado de lesão, secreções, biópsias de pele (micoses subcutâneas); o escarro, lavado brônquico, aspirado brônquico, escovado brônquico (micoses sistêmicas); as secreções, pulmonar, vaginal, traqueal, orotraqueal, de lesões cutâneas, 
abdominal, oral, de conjuntivas ou de qualquer outra localização (micoses sistêmicas); e o sangue, biópsia de qualquer órgão ou tecido, urina, liquor, líquidos sinovial, ascítico, amniótico ou outros líquidos orgânicos (micoses sistêmicas). As infecções fúngicas podem atingir qualquer órgão ou tecido do corpo humano. Portanto, qualquer material biológico pode ser analisado para a pesquisa de fungos.

$\mathrm{Na}$ detecção de microrganismos (bactérias, parasitos, fungos e vírus) utilizamse técnicas laboratoriais que envolvem diversos materiais. Os materiais utilizados contaminam-se, obviamente, com a amostra biológica. Duas situações devem ser levadas em consideração:

- O fato de a amostra biológica ser descartada de forma inadequada;

- $\mathrm{O}$ fato de muitos materiais que tiveram contato com a amostra biológica serem descartados de forma inadequada.

Independente do tipo de Análise Clínica Microbiológica realizada (bacteriológica, parasitológica, fúngica ou virótica), há a demanda da utilização de diversos materiais para a coleta da amostra biológica. O fato é que depois de utilizados, estes materiais devem ser descartados de maneira correta, pois, podem conter resíduos com impacto ambiental e à saúde. Correa (2005) aponta que há profissionais da saúde que desconhecem tamanha responsabilidade.

É importante inferir que na manipulação de amostras biológicas, o
Analista Clínico deve trabalhar biosseguro, pois, segundo Walters et al (1998), a segurança é um ponto fundamental e inclui todas as medidas tomadas para limitar a exposição do trabalhador e do meio ambiente. Neste contexto, a utilização de Equipamentos de Proteção Individual (EPIs) assume fundamental importância.

Luvas, por exemplo, podem conter resíduos infectantes (Moreschi et al, 2014) citando a RDC ANVISA $\mathrm{n}^{\circ} 306 / 04$ e a Resolução CONAMA $n^{\circ}$ 358/05), nelas podem estar qualquer tipo de microrganismo (bactéria, vírus, parasito, fungo) detectado por fezes, sangue, urina, escarro etc. São considerados, de acordo com Costa e Araújo (2008) resíduos do Grupo A (Tabela 2). Isto faz pensar na relevância da utilização deste EPI, bem como em seu descarte adequado. Resíduos do grupo A, conforme Silva (2004), não podem ser dispostos no meio ambiente sem tratamento prévio, e recomenda-se a esterilização a vapor ou incineração, como alternativa de tratamento. No entanto, outros processos de tratamento poderão ser adotados, desde que, com aprovação prévia dos órgãos ambiental e de saúde competentes. Em relação aos aterros sanitários, estes deverão ter previstos sistemas específicos que permitam a disposição de resíduos sólidos pertencentes ao grupo A. Os resíduos pertencentes a este grupo não poderão ser reciclados e, após tratamento, serão considerados resíduos comuns. 
Como exemplo de outro tipo de resíduo do grupo A, pode-se citar a utilização do swab no processo de inoculação do meio de cultura em bacteriologia.

Como já exposto, além de resíduos sólidos, o Laboratório de Análises Clínicas produz também resíduos líquidos. É o caso dos resíduos do grupo B (Tabela 2). Nesta acepção, em Análises Clínicas Microbiológicas são utilizados reagentes e recipientes. Por exemplo: A coloração de Gram é a coloração mais frequentemente utilizada no Laboratório de Análises Clínicas, onde reagentes são utilizados no intuito de diferenciar as estruturas das paredes das células bacterianas (WALTERS et al, 1998).

De modo geral, é fundamental que todos os materiais utilizados nas Análises Clínicas Microbiológicas sejam descartados em recipientes próprios, devidamente etiquetados, uma vez que Laboratórios de Análises Clínicas oferecem riscos, por serem potencialmente infectantes (presença de agentes patogênicos), genotóxico (capacidade de alterar o DNA), conter tóxicos ou químicos perigosos, e conter material perfurocortante (CAVALCANTI, 2003).

De acordo com Cavalcanti et al (2009), a classificação de resíduos minimiza riscos à saúde pública e ao meio ambiente. Entretanto, a questão também reside no fato de se formar profissionais analistas clínicos, dotados de capacidade crítica e reflexiva sobre as consequências socioambientais do descarte inadequado de resíduos, superando o tecnicismo, do racional para o afetivo. Assim, não basta apenas que políticas públicas específicas sobre o assunto sejam formuladas (PERES et al (2014). Antes disso, há a necessidade da capacitação/formação profissional.

Do contrário, Laboratórios de Análises Clínicas continuarão poluindo e contaminando o meio ambiente, no momento em que seus resíduos são descartados inadequadamente em pias, lixo comum etc., sem nenhuma preocupação com as consequências socioambientais (MARQUES e VAZ, 2009). Estes mesmos autores apontam que as Universidades, como instituições responsáveis pela formação de seus estudantes e, consequentemente, pelo seu comportamento como cidadãos, devem também estar conscientes e preocupadas com este problema. As atividades de laboratório realizadas geram resíduos que podem oferecer riscos ao meio ambiente ou a saúde.

Um estudo que envolveu pesquisa sobre a percepção ambiental de trabalhadores de Laboratórios de Análises Clínicas, demonstrou que metade dos entrevistados considera práticas de proteção ambiental importantes, e mais da metade desta mesma população reconhecem que as práticas geram impactos (CAVALCANTI et al, 2009).

Neste estudo, embora os entrevistados tenham apontado as ações de proteção ambiental como um fator importante para a competitividade do setor, parte deles não as desenvolvem com frequência, ou seja, 
profissionais de saúde reconhecem, mas não agem. Cavalcanti et al (2009) obtiveram uma informação considerada fundamental: a baixa frequência de capacitação profissional nos Laboratórios de Análises Clínicas pesquisados.

Tomando por base as concepções de Spironello et al (2012), a capacitação envolve o processo de sensibilização para que a conscientização ocorra, enfocando não apenas mudanças de comportamentos, mas sim, tomada de atitudes advindas de transformações de valores. Esse processo envolve reflexão crítica sobre o manejo inadequado dos resíduos de Análises Clínicas Microbiológicas e suas consequências à saúde socioambiental.

\section{RESULTADOS E DISCUSSÃO}

No que diz respeito às consequências para a saúde socioambiental, há uma carência de publicações, resultando na não interface existente entre as Análises Clínicas Microbiológicas, RSS e Saúde socioambiental.

No âmbito das Análises Clínicas Microbiológicas, Moreschi et al (2014) despertam para o fato da importância de uma capacitação profissional consciente para o descarte racional de resíduos gerados. A capacitação profissional na área de saúde deve ir além de uma formação tecnicista. Deve envolver o processo de reflexão crítica.
Para que analistas clínicos laboratoriais se conscientizem sobre o descarte correto de resíduos, ou, em outras palavras, para que conheçam o significado da expressão "resíduos" é necessário que haja sensibilização. Só assim, a conscientização acontece (SPIRONELLO et al, 2012),

Conscientização, no que diz respeito às consequências socioambientais, uma vez que RSS, como por exemplo, os presentes em luvas, devem ser, de forma imprescindível, levados em consideração. Moreschi et al (2014) citando a RDC ANVISA no 306/04 e a Resolução CONAMA no $358 / 05$, relatam que em luvas podem estar presentes quaisquer tipos de microrganismos (bactéria, vírus, parasito, fungo) detectados por fezes, sangue, urina, escarro etc.

A capacitação profissional tecnicista é resultado de uma formação não sensibilizadora, não reflexiva e não crítica, do significado do conteúdo de ensino (MORESCHI et al, 2014). No que diz respeito às Análises Clínicas Microbiológicas, é importante que a detecção de uma bactéria, por exemplo, vá além da comparação por padrões de referência estipulados por uma planilha morfológica, qualitativa e quantitativa.

Um analista clínico, ao executar uma técnica laboratorial microbiológica, deve ser capaz de refletir sobre a sua própria prática (Figura 1). 
Figura 1 - A importância do processo de reflexão crítica na formação/capacitação do profissional analista clínico, tomando como exemplo a técnica de identificação bacteriana referente às provas bioquímicas.

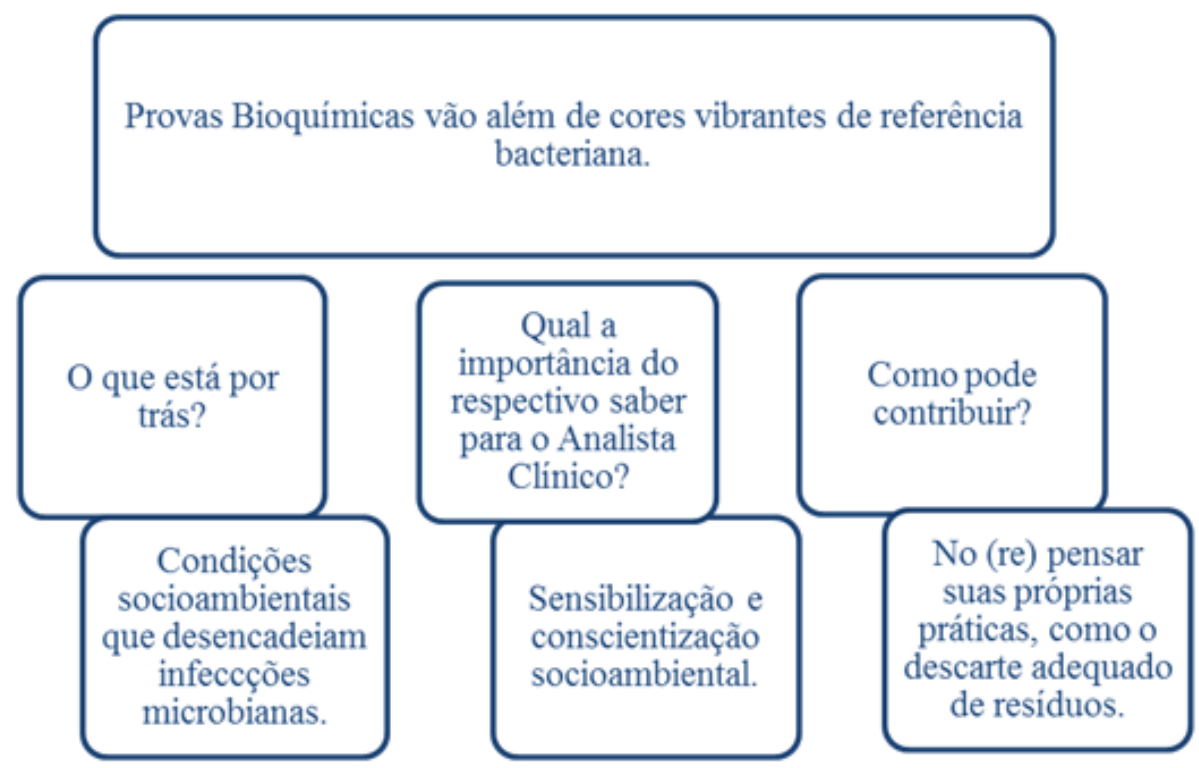

*Fonte - Próprios autores.

Por trás de resultados positivos advindos de provas bioquímicas microbiológicas, estão condições socioambientais que correspondem à realidade cercante em que o indivíduo examinado vive, como disposição de saneamento básico. Por isso, na detecção microbiológica de fungos, bactérias, vírus ou parasitos, é importante que o profissional Analista Clínico não apenas execute técnicas de forma mecanizada, mas também tenha a sensibilidade de que seus próprios atos podem agravar ainda mais a situação socioambiental, responsável pelo desencadeamento de diversos tipos de infecções detectadas rotineiramente no laboratório.
Moreschi et al (2014) apontam que profissionais de saúde reconhecem que existe negligência nos procedimentos realizados que geram impacto ambiental e suas repercussões para a sociedade. Essa negligência, como já apontado, acontece por tratar-se de mudança de paradigma que resulta em resistências e desafios, fruto de falhas na formação/capacitação do analista clínico.

É condizente expor que muitos profissionais chegam a fazer o descarte de resíduos do tipo $\mathrm{A}, \mathrm{B}, \mathrm{D}$ e $\mathrm{E}$ em lixeiras específicas. No entanto, com base no apontamento de Moreschi et al (2014), muitos desconhecem o significado da expressão "resíduos", o que nos induz a pensar num descarte mecanizado e tecnicista, não 
reflexivo, acrítico, não consciente, focando apenas no cumprimento de procedimentos operacionais padrão (POPs).

Inclui-se aí, a questão da veiculação microbiana em resíduos advindos de placas de petri contendo meio de cultura, coletores contendo restos de urina e fezes, luvas, algodão, gaze, swabs, espátulas, contaminados com sangue ou secreções; reagentes usados nas análises e os recipientes contaminados por estes, além dos efluentes dos equipamentos automatizados; papéis, papelão, copos plásticos, garrafas plásticas, embalagens plásticas e caixas dos kits de reagentes não contaminados; papel toalha, papéis sanitários, restos alimentares, papel laminado de embalagens dos kits de reagentes e outros similares; recipientes de vidro contendo restos de soros controle, calibradores, agulhas, escalpes, ampolas de vidro, lancetas, lâminas, lamínulas, todos os utensílios de vidros quebrados no laboratório (pipetas, tubos de ensaio, tubos de coleta de sangue) e outros similares (COSTA E ARAÚJO, 2008).

Assim, a organização de conceitos advindos desta revisão, possibilitou um despertar epistemológico, ou seja, permitiu o despertar para a (re) construção de um conhecimento que deve ser aprofundado ${ }^{(5)}$ mediante reconhecimento e interação do que expõem estudiosos, evidenciando assim, a relevância desta pesquisa: ${ }^{(4)}$ despertar para a importância da interface entre as Análises Clínicas Microbiológicas, RSS e Saúde socioambiental (Figura 2).

Figura 2 - A interface existente entre as Análises Clínicas Microbiológicas, RSS e Saúde socioambiental. A seta verde representa as Análises Clínicas adentrando nas temáticas Saúde socioambiental e RSS; vice-versa: a seta vermelha representa as temáticas Saúde socioambiental e RSS adentrando nas Análises Clínicas Microbiológicas.

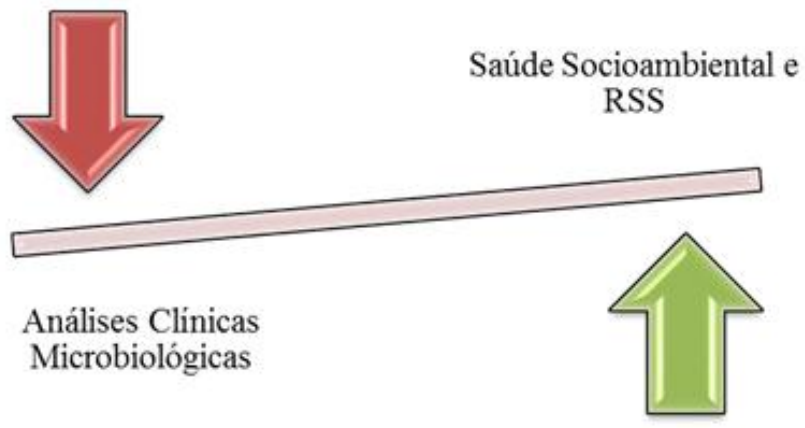

*Fonte - Próprios autores.

A Figura 2 foi elaborada com o intuito de emergir o pensamento da complexidade, indo contra a fragmentação das temáticas Análises Clínicas Microbiológicas,
RSS e Saúde Socioambiental, numa perspectiva epistemológica, e não tecnicista.

Supera-se assim, o paradigma tecnicista em como os profissionais de saúde, 
no caso, analistas clínicos, tratam as temáticas Saúde socioambiental e RSS.

O tecnicismo é um paradigma que orienta a educação tradicionalista, numa visão reducionista e acrítica, que repercute em profissionais de saúde incapazes de reconhecer à existência de negligência nos procedimentos realizados que geram consequências socioambientais. Essa negligência acontece por tratar-se de mudança do paradigma cartesiano, que reflete na cultura, em resistências e desafios (MORESCHI et al 2014).

Tomando por base as concepções de Cavalcanti et al (2009), os possíveis motivos que levam profissionais de saúde a reconhecer a existência de impacto socioambiental advindo de resíduos laboratoriais, mas não tomarem atitude perante a situação, destacase:

\section{- O descomprometimento do} Laboratório no que diz respeito a geração de seus resíduos;

- A formação tecnicista profissional;

- O processo de capacitação dos profissionais de Laboratório de Análises Clínicas baseado no aprender e não no apreender.

\section{CONSIDERAÇÕES FINAIS}

De acordo com o estudo realizado, observa-se que o despertar para a conscientização sobre o descarte racional de RSS, por profissionais analistas clínicos, envolve em sua formação, o processo de sensibilização. Isto porque a conscientização não acontece de fora para dentro, mas ao contrário. Neste sentido, o acometimento à saúde socioambiental se dá justamente pelo fato de profissionais de saúde não saberem o significado de "resíduos" em seu sentido holístico, uma vez que:

- $\quad$ Reconhecem, mas não agem;

- Aprendem, mas não apreendem.

A pesquisa realizada mostrou que há necessidade de aprofundamento de discussões sobre o assunto quanto à interface entre as Análises Clínicas Microbiológicas, RSS e Saúde socioambiental, num estudo categórico e integrador entre os tópicos:

- Tipos de resíduos provenientes de cada tipo de Análise Clínica Microbiológica (bacteriológica, virológica, parasitológica, fúngicas);

- Microrganismos veiculados nos resíduos produzidos por Análises Clínicas Microbiológicas;

- Consequências socioambientais como resultado da veiculação de microrganismos provenientes de resíduos advindos de Análises Clínicas Laboratoriais.

Para concluir, cabe a exposição do questionamento: Como sensibilizar profissionais de saúde Analistas Clínicos quanto à influência socioambiental de suas práticas laboratoriais, indo além de uma formação/capacitação enfocada apenas no cumprimento de POPs? 


\section{REFERÊNCIAS}

BENTO, A. Como fazer uma revisão da literatura: considerações teóricas e práticas. Rev JA (Associação Académica da Universidade da Madeira). 2012;(65):1-4.

CAVALCANTI, D. G. K. Gestão ambiental na saúde pública: um estudo sobre a percepção ambiental em laboratórios de análises clínicas. 2003. Dissertação (Mestrado em Gestão Ambiental) - Universidade Federal do Rio Grande do Norte, Caiocó, 2003.

CAVALCANTI, D. G. K. et al. Estudo sobre a percepção ambiental em laboratórios de análises clínicas. Engenharia Ambiental: Pesquisa e Tecnologia. 2009 jan/abr;6(1):15468.

COSTA, E. C. L.; ARAÚJO, J. A. F. Programa de gerenciamento de resíduos do laboratório de análises clínicas da câmara dos deputados. Brasília. Dissertação [Especialização em Análises Clínicas] Universidade Tuiuti do Paraná; 2008.

CORRÊA LB. A educação ambiental e os resíduos sólidos de serviços de saúde: a formação acadêmica. Rio Grande. Dissertação (Mestrado em Educação Ambiental) Fundação Universidade Federal do Rio Grande; 2005.

JACOBI PR, BESSEN GR. Gestão de resíduos sólidos em São Paulo: desafios da sustentabilidade. Estudos Avançados. 2011;25(71):135-58.

LIMA GAB. Modelos de categorização: apresentando o modelo clássico e o modelo de protótipos, Perspectivas em Ciência da Informação. In: Anais do $25^{\circ}$ Congresso Brasileiro de Engenharia Sanitária e Ambiental; 2009; Rio de Janeiro, Brasil. Rio de Janeiro: Sociedade Brasileira de Engenharia Sanitária e Ambiental; 2009.

MARQUES ACF, VAZ LMS. Gestão de resíduos laboratoriais em instituição de ensino superior: análise do sistema de gestão dos resíduos laboratoriais da faculdade de tecnologia e ciências. In: Anais do $25^{\circ}$

Congresso Brasileiro de Engenharia Sanitária e Ambiental; 2009; Rio de Janeiro, Brasil. Rio de Janeiro: Sociedade Brasileira de Engenharia Sanitária e Ambiental; 2009. pp. 1-7.

MORESCHI C, REMPEL C, BACKES DS, CARRENO I, SIQUEIRA DF, MARINA B. A importância dos resíduos de serviços de saúde para docentes, discentes e egressos da área da saúde. Rev Gaúcha de Enfermagem. 2014;35(2):21-2.

MULLER AM, SILVEIRA DD, NARA EOB, KIPPER LM, MORAES JARL. Um olhar exploratório sobre os resíduos de serviços de saúde para os cursos da área da saúde numa universidade comunitária do Sul do Brasil. Rev Eletrônica em Gestão, Educação e Tecnologia Ambiental. 2014 dez;17(17):3327-35.

ORGANIZAÇÃO NACIONAL DE ACREDITAÇÃO. 2011. [Acesso em 08 de jul de 2014]. Disponível em: <https://www.ona.org.br/Inicial>.

PERES RR, CAMPONOGARA S, CIELO C, SILVA, NM, LOURENSI CM, ROSSATO, GC. Percepções de trabalhadores e estudantes atuantes em um pronto-socorro, sobre meio ambiente e saúde. Rev Min Enferm. 2014 jan/mar;18(1):27-33.

SANTOS V. O que é e como fazer "revisão da literatura" na pesquisa teológica. Rev Fides Reformativa XVII. 2012;1:89-104.

SILVA GG. Diagnóstico de resíduos sólidos laboratoriais da área da saúde na Universidade do Extremo Sul Catarinense. Criciúma. Monografia [graduação em Engenharia Ambiental] - Universidade do Extremo Sul Catarinense - UNESC; 2004

SPIRONELLO RL, TAVARES FS, SILVA EP. Educação ambiental: da teoria à prática, em busca da sensibilização e conscientização ambiental. RevGeonorte. 2012;Edição Especial,3(4):140-152. 
WALTERS NJ, ESTRIDGE BH,

REYNOLDS AP. Laboratório clínico:

técnicas básicas. 3. ed. Porto Alegre: Artmed;

1998. 